Journal of Neurocytology 6, 129 (1977)

\title{
Erratum
}

\section{Some cytochemical and cytological features of the so-called SIF cells of the superior cervical ganglion of the rat}

\author{
JACQUES TAXI and MARIA MIKULAJOVA
}

Journal of Neurocytology 5, 283-295

We apologize for the omission of Figs $13-18$ in the above paper. They are printed overleaf, and the caption to the plate is given below.

Fig. 13. Several dense patches along the contact between two SIF cells. $\times 44000$.

Fig. 14. (compare with Figs. 11 and 12). In spite of the presence of two presynaptic dense projections, no postsynaptic 'membrane thickening' is present at this presumed synapse. $x 40000$. Fig. 15. An isolated dense patch in a row of several normal dense-cored vesicles. The nature of the opposed element is undetermined. $x 40000$.

Fig. 16. ( 333000$)$ and Fig. 17 ( $\times 41000$ ). Isolated dense patch at a zone of contact between a SIF cell and a probable glial cell. In Fig. 17, narrow pale layer surrounds the dense patch.

Fig. 18. Several regularly spaced dense patches in SIF cell in contact with an undetermined structure (probably a SIF cell or neuronal process). $\times 32000$. 


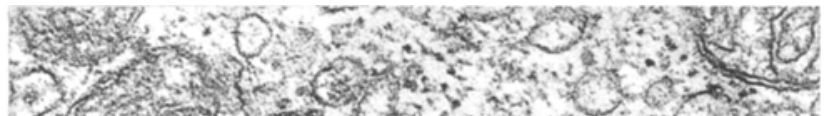

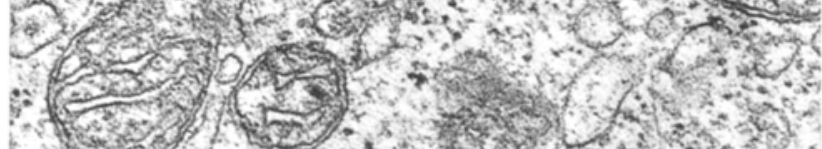

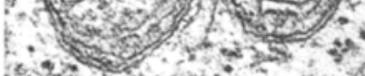

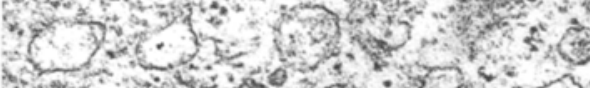

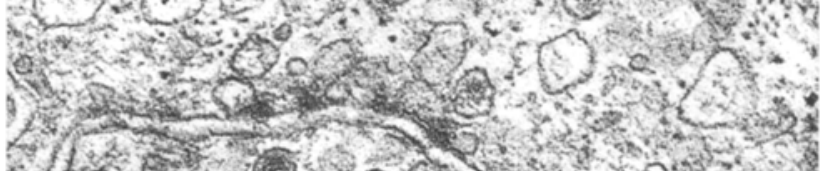

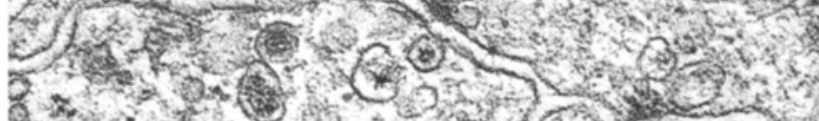

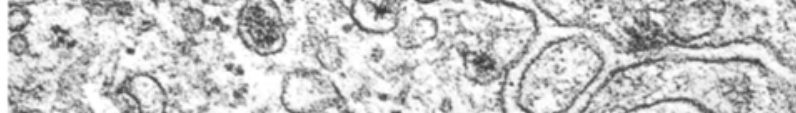

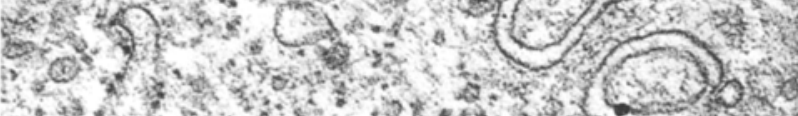

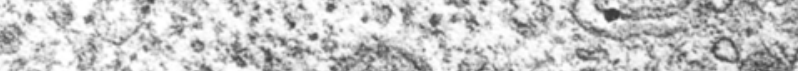
3.

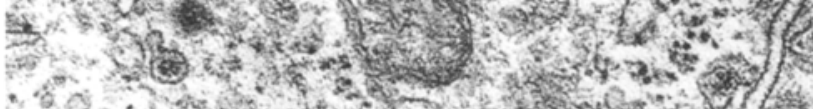

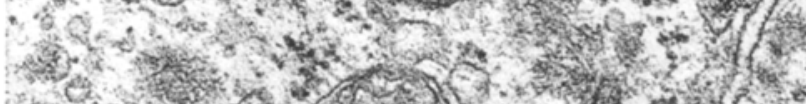
13.

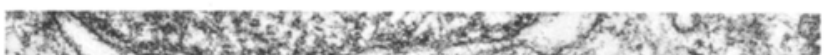

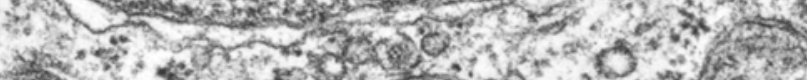

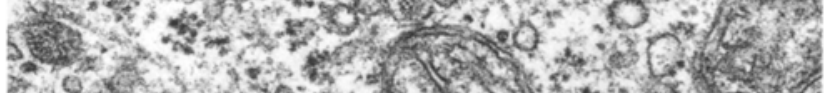

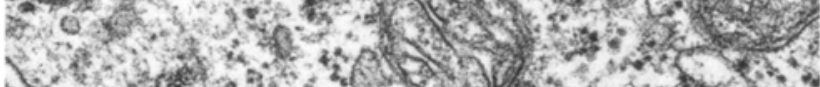

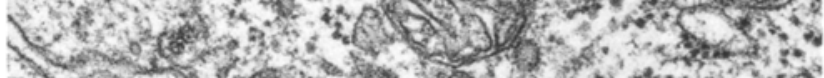

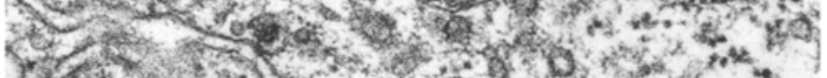

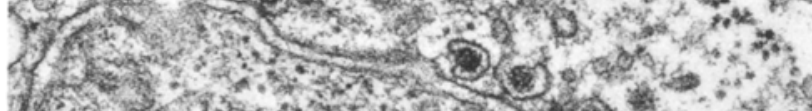

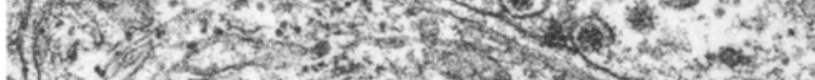

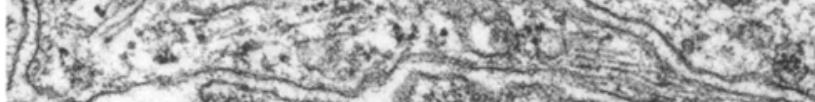

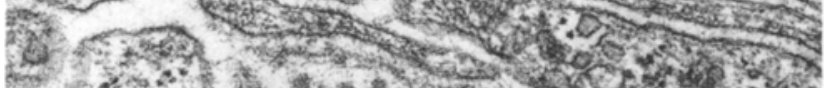

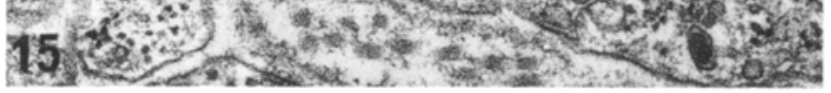
moldy

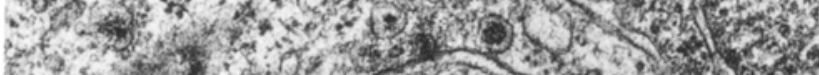

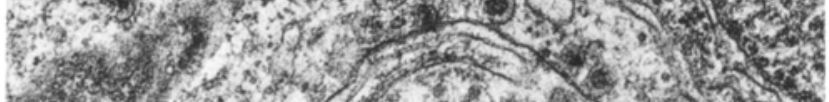
W.

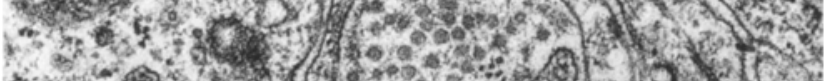
x.

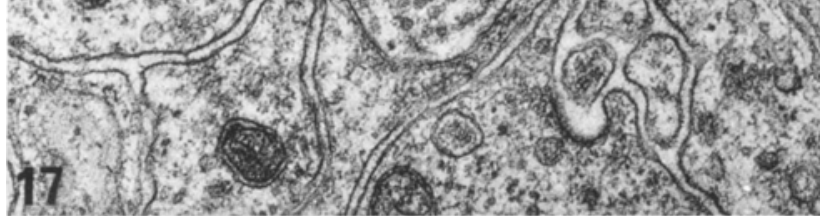

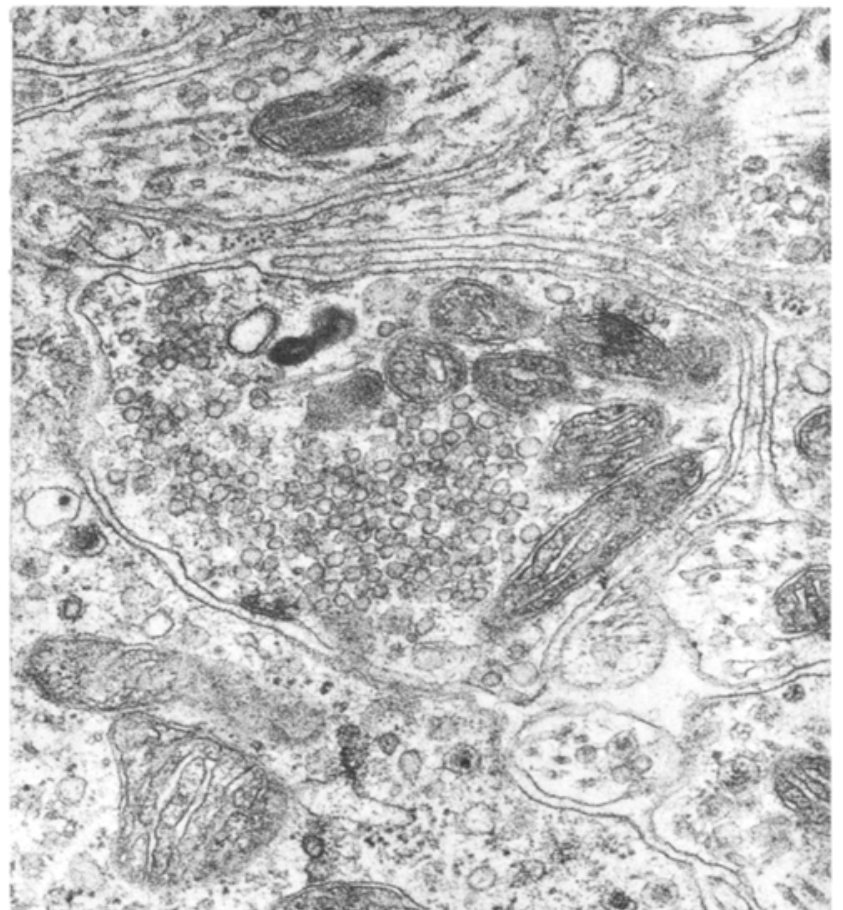

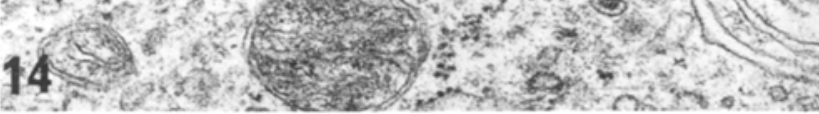

\section{3}

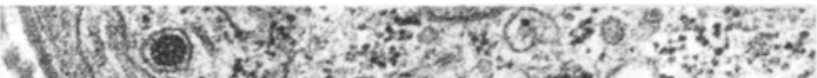

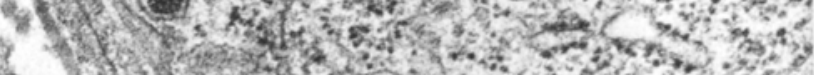

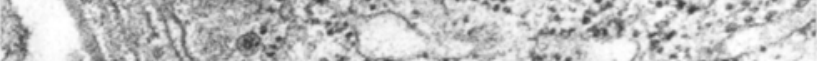
25. (f)

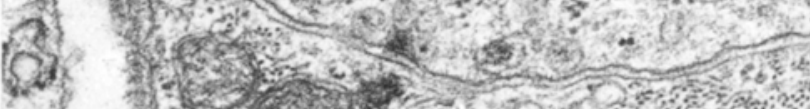

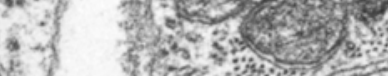

is

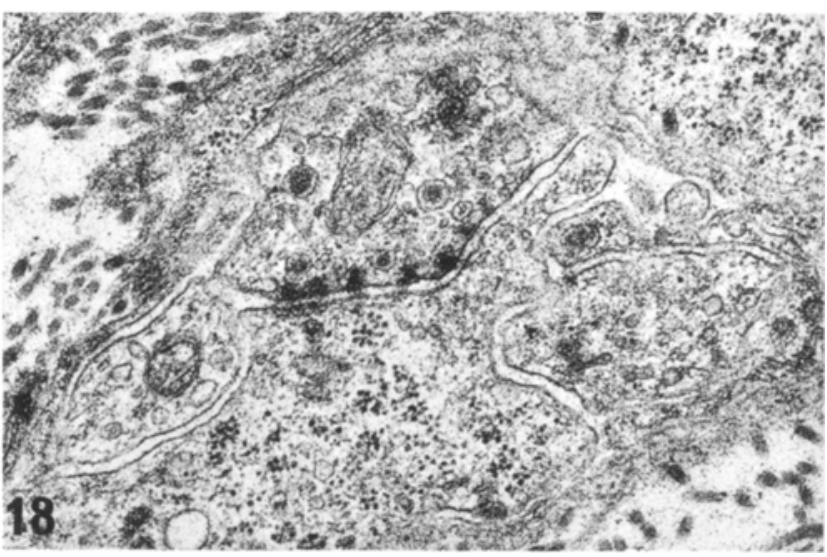

